\title{
Acompanhamento hospitalar: direito ou concessão ao usuário hospitalizado?
}

\author{
Hospital treatment: \\ right or concession to the hospitalized user?
}

Ieda Cristina Pereira Sanches ${ }^{1}$

Ingrid Ramos Reis Couto ${ }^{1}$

Ana Lúcia Abrahão ${ }^{1}$

Marilda Andrade ${ }^{1}$

${ }^{1}$ Escola de Enfermagem Aurora de Afonso Costa, Universidade Federal Fluminense. Rua Dr. Celestino 74, Centro. 24020-091 Niteroi RJ. ieda_cps@hotmail.com

\begin{abstract}
The study sought to understand - from the viewpoint of the hospitalized user - the perception and the difficulties involved in administering hospital attendance in surgical inpatient units at a public hospital in the city of Niteroi, R.J., and discuss them in light of the concepts of Institutional Analysis (IA). Maintaining the emotional and social bonds of the hospitalized individual is essential and is encouraged by public health policies. However, discussions are needed about how to take maximum advantage of this possibility. In the descriptive research using a qualitative approach, the techniques of semistructured interviews and field observations were used and the resulting data were classified using Content Analysis. Three thematic areas were identified for discussion, namely the presence of nurses for care requests, interference in communication between the companions and nurses, and the conditions of comfort afforded to the companion. The conclusions drawn from the studies relating to the presence of the companion together with the hospitalized user are that it is indispensable to include companions and the nursing team in the discussions and the creation of strategies to make this user right a reality.
\end{abstract}

Key words Hospitalization, Humanization, Nursing team and patient companions
Resumo O estudo objetivou conhecer a percepção e as dificuldades ao exercício do acompanhamento hospitalar nas unidades de internação cirúrgica de um hospital público do município de Niterói, RJ, sob a ótica do usuário internado e discuti-las à luz dos conceitos da Análise Institucional (AI). Manter os vínculos afetivos e sociais do indivíduo hospitalizado é fundamental e incentivado pelas políticas públicas de saúde. No entanto, são necessárias discussões a respeito de como tirar proveito máximo desta possibilidade. A pesquisa descritiva, de abordagem qualitativa, utilizou as técnicas de entrevista semiestruturada e observação de campo. Os dados foram categorizados através da Análise de Conteúdo. Identificamos 03 núcleos temáticos para discussão: presença da enfermagem para atendimento às solicitações, ruídos na comunicação entre os acompanhantes e a enfermagem e condições de conforto ao acompanhante. Concluímos que os estudos referentes à presença do acompanhante junto ao usuário internado tornam indispensável a inclusão dos segmentos de acompanhantes e equipe de enfermagem nas discussões e a criação de estratégias que torne este direito do usuário uma realidade. Palavras-chave Hospitalização, Humanização, Equipe de enfermagem, Acompanhantes de pacientes 


\section{Introdução}

Nas últimas décadas e em especial a partir dos anos 90 do século XX, tem-se valorizado o papel do acompanhante como facilitador no restabelecimento da saúde de pacientes internados em unidades hospitalares, assim como agente acelerador no processo de reabilitação. Tais conclusões são respaldadas pelas orientações das políticas públicas de saúde, inicialmente semeadas pela implantação da Lei do Sistema Único de Saúde (SUS) na qual está garantida a integralidade da assistência, sendo esta entendida como o "conjunto articulado e contínuo das ações e serviços preventivos e curativos, individuais e coletivos, exigidos para cada caso em todos os níveis de complexidade do sistema" e que pressupõe o indivíduo como portador de demandas físicas, emocionais, relacionais e materiais ${ }^{1}$.

Manter o vínculo afetivo e social do usuário que necessite permanecer no ambiente hospitalar, na maioria das vezes centrados em práticas disciplinares que muito diferem das domiciliares, é fundamental e amplamente incentivado pelas políticas públicas de saúde que reconhecem a importância do acompanhante na dinâmica do cuidado. No entanto, são necessárias discussões a respeito de como ampliar as possibilidades de ação deste ator na recuperação da saúde do sujeito internado.

Além do suporte emocional possibilitado ao usuário pelo seu acompanhante, com redução dos sintomas de abatimento e ansiedade frequentes nessa situação, observa-se que o sucesso do tratamento pode ser influenciado fortemente pelo comportamento do acompanhante ${ }^{2}$.

Durante a fase de planejamento da alta hospitalar é de suma importância que o acompanhante seja visto não só como agente cuidador, mas como potente facilitador da evolução clínica e reinserção social do usuário. Portanto, a sua participação nessa fase deve ser reconhecida, incentivada e discutida coletivamente durante o processo da internação.

Sendo assim, a parceria entre a equipe de saúde e o acompanhante é um objetivo a ser almejado durante a permanência do sujeito internado e posteriormente a ela ${ }^{2}$.

Neste artigo, buscamos conhecer a percepção do usuário sobre os aspectos que envolvem a presença do acompanhante ao seu lado durante a internação, bem como as dificuldades observadas em seu exercício cotidiano. Acreditamos que somente proporcionando uma assistência centrada nas necessidades do usuário, é tangível o princípio da integralidade assistencial.
O texto inicia com uma breve discussão a cerca dos aspectos legais e sociais que envolvem o acompanhamento hospitalar e posteriormente são apresentados os problemas apontados pelos usuários em seus depoimentos. Estes são contextualizados com as práticas hospitalares relacionadas ao exercício do acompanhamento e discutidos de acordo com os princípios da Análise Institucional.

\section{O Usuário, o Direito e o Cuidado Integral}

$\mathrm{O}$ direito à permanência do acompanhante no ambiente hospitalar já é reconhecido para algumas parcelas de usuários do sistema de saúde brasileiro. Idosos, gestantes, crianças e indivíduos com necessidades especiais não necessitam de autorizações especiais para possuírem acompanhantes nos hospitais.

O paciente adulto, de modo geral, usufrui do acompanhamento como uma concessão. Nesses casos, a negociação é muitas vezes desgastante e dependente das condições estruturais do hospital ou da necessidade do acompanhante em suprir o déficit de profissionais de enfermagem; em ambos os casos, não são consideradas prioritariamente as necessidades do indivíduo internado.

As orientações da Cartilha sobre Visita Aberta e o Direito ao Acompanhante, que se originou da Política Nacional de Humanização (PNH) apontam para "a necessidade da criação de um ambiente relacional" que viabilize ao cliente a possibilidade de redescobrir o sentido e o valor de sua existência neste momento desfavorável imposto pela hospitalização. O documento reconhece a falta de estrutura física e de profissionais destinados ao acolhimento destes acompanhantes ${ }^{3}$.

Essas deficiências estruturais tornam-se evidentes durante o desenvolvimento das atividades dos profissionais de saúde, mas agrava-se em relação ao trabalho da equipe de enfermagem, que se encontra presente em período integral e divide o mesmo espaço com clientes e familiares. Lembremo-nos de que o profissional de enfermagem, cercado de agentes estressores já conhecidos, tais como sobrecarga de tarefas, escassez de insumos básicos à realização de seu trabalho e baixa remuneração, também é exposto a uma carga emocional de sofrimento, dor e morte com as quais convive cotidianamente. Sendo assim, não são raros os casos em que as relações interpessoais entre os membros da equipe o os acompanhantes apresentam ruídos, comprometendo o cuidado ao usuário internado ${ }^{4}$. 
Se fizermos um retrospecto ao final do século XVII, perceberemos que a valorização da proximidade do paciente ao seio familiar foi defendida por uma parcela dos estudiosos do campo da saúde e que a hospitalização, devido à sua impessoalidade, chegou a ser considerada iatrogênica e agravadora dos males ${ }^{5}$.

$\mathrm{Na}$ atualidade, entendemos que a internação hospitalar pode ser um dos recursos necessários à recuperação do estado de saúde do usuário. Não podemos ignorar os benefícios trazidos pelos desenvolvimentos científico e tecnológico, mas temos que colocar em discussão os componentes afetivos e humanísticos do ato de cuidar no campo da saúde.

A integração a um ambiente que propicie conforto, segurança e afetividade, além de assistência é então indispensável para a promoção e a recuperação da saúde individual e coletiva. Este ambiente na quase totalidade dos casos requer a existência de referências domiciliares ou da comunidade da qual faz parte o usuário internado.

Dessa forma, podemos como profissionais de saúde, contribuir com estratégias para que os efeitos do acompanhamento ao usuário hospitalizado, além de instituído formalmente alcance de fato o seu valor terapêutico.

$\mathrm{O}$ vínculo relacional, ponto crucial para o desenvolvimento do acompanhamento ao usuário, perpassa pela combinação de componentes afetivos e sociais impostos pela necessidade de adaptação dos hábitos de vida doméstica à rotina pesada do ambiente hospitalar. E exatamente por referir-se a um grupo composto por subgrupos heterogêneos, encontramos na Análise Institucional ou Institucionalismo, o suporte para a compreensão dos fenômenos gerados por essa convivência, pois para Baremblitt ${ }^{6}$ :

O movimento Institucionalista é um conjunto heterogêneo, heterológico e polimorfo de orientações, entre as quais é possível se encontrar pelo menos uma característica comum: sua aspiração a deflagrar, apoiar e aperfeiçoar os processos autoanaliticos e autogestivos dos coletivos sociais.

Faz-se necessário que a permanência do acompanhante junto ao usuário seja reconhecida como um direito. Sendo assim, o ambiente hospitalar deve adaptar-se e seus profissionais precisam discutir e adotar estratégias que viabilizem a presença de novos atores, acompanhando a evolução das ações em direção à humanização da assistência.

\section{Caminho metodológico}

O estudo proposto caracteriza-se como descritivo, pois pretendeu estimular o pensamento científico através do aprofundamento de um problema observado no cotidiano, sendo mapeados, analisados e interpretados aspectos ligados à determinada população ${ }^{7}$. Nesse caso, foram descritas as impressões da população de usuários internados a respeito do acompanhante e sua permanência no ambiente hospitalar.

Nessa perspectiva e por procurar construir um conhecimento a partir do empirismo cumprindo etapas sistematizadas, considerando componentes psicossociais e a partir de um grupo delimitado, foi utilizada o abordagem qualitativa ${ }^{8}$.

Foi realizada a técnica de entrevista semiestruturada devido à natureza delicada da abordagem do tema, que envolve aspectos subjetivos dos atores envolvidos e fatores estruturais do ambiente hospitalar. Nesse tipo de entrevista, o pesquisador tem possibilidade de voltar o foco ao objeto de estudo quando o entrevistado desviar-se do mesmo ${ }^{7}$.

Os autores utilizaram também a observação de campo, detendo-se na forma como se desenvolvem as etapas do processo de internação desde a admissão do usuário até o momento da cirurgia proposta. Além dos relatos dos usuários entrevistados, foram levadas em consideração informações contidas nos prontuários e registros das unidades.

A pesquisa desenvolveu-se nas unidades de internação cirúrgica de um hospital público do Município de Niterói, RJ. Tal escolha deveu-se ao fato de que as enfermarias cirúrgicas abrigam usuários que migram abruptamente da situação de autonomia para a de dependência total no pós-operatório, o que os torna vulneráveis às alterações de humor ou complicações clínicas se não forem adequadamente assistidos.

Os sujeitos da pesquisa foram 08 usuários hospitalizados nas unidades de internação cirúrgicas, que contavam com acompanhamento de amigos ou familiares em período integral.

A coleta de dados estendeu-se de Setembro a Novembro de 2011. Em alguns casos, foram realizados vários contatos prévios a cada entrevistado, objetivando a criação de vínculo de confiança capaz de romper a autocensura percebida às informações. Apesar do interesse em participar da pesquisa, a agenda de exames e procedimentos destinados ao usuário, assim como suas condições clínicas também foram determinantes para que algumas entrevistas fossem realizadas em etapas. 
O instrumento de coleta de dados constou de 09 perguntas enfocando o vínculo relacional entre o usuário e seu acompanhante, os motivos que o levaram a desejar o acompanhamento, indagando sobre a satisfação de suas expectativas em relação à permanência do acompanhante e sobre intercorrências envolvendo os mesmos e que o houvessem desagradado. Realizamos um pré-teste entrevistando 02 usuários na primeira semana de Setembro de 2011, com o objetivo de identificar e corrigir vieses que pudessem interferir na pesquisa. Esta fase foi realizada em enfermaria de pacientes cirúrgicos e não foi incluída na fase final da coleta de dados. Dessa forma, a leitura crítica do material do pré-teste possibilitounos identificar os equívocos e os acertos contidos no roteiro de entrevista utilizado neste estudo.

Para a análise dos dados, utilizamos a técnica de Análise de Conteúdo (AC), surgida no início do século XX. Das várias modalidades de AC conhecidas, a análise temática nos pareceu a mais apropriada à pesquisa ora apresentada, a qual consiste na identificação dos núcleos de sentido identificados e que estão presentes no processo estudado, possuindo relação com o objeto de estudo escolhido. Estes núcleos de sentido são então relacionados com características comportamentais ou outras estruturas relevantes apreendidas no discurso ${ }^{8}$.

Pela análise nas respostas fornecidas pelos usuários entrevistados, foram caracterizados 03 núcleos temáticos para discussão, a saber: a presença da enfermagem para o atendimento às solicitações, ruídos na comunicação entre os acompanhantes e a enfermagem e as condições de conforto do acompanhante. O exame dos dados, a partir dos núcleos de sentido identificados na Análise de Conteúdo, foi debatido à luz de conceitos da Análise Institucional (AI), movimento surgido nos anos 40 do século passado e desenvolvido por René Lourau nos anos $60^{9}$.

A realização das entrevistas ocorreu após a apresentação dos objetivos do estudo pelo pesquisador aos sujeitos, assim como a autorização dos entrevistados mediante assinatura do Termo de Consentimento Livre e Esclarecido.

$\mathrm{O}$ projeto de pesquisa foi aprovado pelo $\mathrm{Co}$ mitê de Ética da instituição utilizada como cenário. São respeitados no estudo os princípios da Resolução no 196/96 do Conselho Nacional de Saúde ${ }^{10}$.

\section{Os núcleos de sentido presentes no estudo}

Foram realizadas várias leituras do material bruto das entrevistas, seguida de leitura flutuante e, por fim, a identificação dos núcleos de ideias para a análise. Os resultados foram agrupados como se segue:

\section{A presença da enfermagem} para o atendimento às solicitações

Este bloco temático é caracterizado pelos estratos das entrevistas abaixo:

... as enfermeiras são muito cuidadosas, mas elas tem mais o lado profissional, não? Eu gosto assim de fazer brincadeiras para quebrar o gelo em casa e a coisa ficar assim... mais leve. (depoente C)

Evidencia-se neste depoimento que o mencionado "lado profissional" da equipe tem sido associado restritamente à realização de procedimentos técnicos. Apesar da realização dos mesmos em tempo considerado hábil, o usuário mantém a necessidade de alguém com quem compartilhar o peso da internação, tornando-a suportável.

Este depoimento também traz à tona o distanciamento do profissional de saúde em relação ao usuário. Os mesmos recursos tecnológicos que possibilitam a economia de tempo na execução de tarefas podem ocasionar a evasão do profissional de saúde do contato direto e prolongado com os indivíduos sob os seus cuidados ${ }^{11}$.

Para Abrahão, a angústia é uma pesada nuvem que paira sobre todos na atmosfera hospitalar e é expressada sob diferentes formas. Alguns tentam escondê-la através de palavreado hermético, outros através de vagas informações ou ainda procurando distanciar-se dela. No entanto, todos a sentem ${ }^{12}$. Dessa forma, em alguns casos aparentes de indiferença e afastamento, pode ocultar-se a incapacidade humana em lidar com o sofrimento extremo e a angústia que isso pode gerar.

Eu não senti a necessidade de um acompanhante antes da cirurgia. O pessoal aqui [equipe] vem quando a gente chama, quando a gente precisa. Às vezes demora um pouco, mas se a gente insistir eles aparecem. Se for importante mesmo eles aparecem (depoente E).

Quais os parâmetros que definem o que "é realmente importante" para o usuário e de que maneira é possível realizar a avaliação à distância? O depoente sugere em sua fala que a partir da insistência da solicitação, a equipe irá atendêlos ou não.

O fato do grupo "equipe de enfermagem" decidir pelo grupo "usuários" o que é importante 
ou não para ele, retira-lhe a voz, impedindo-o de tornar-se sujeito no contexto da hospitalização. Por outro lado, essa atribuição de níveis de importância às solicitações dos usuários pode estar relacionada à sobrecarga de atividades imposta a um número reduzido de profissionais de enfermagem, conforme o observado durante o trabalho de campo, que elegem as prioridades na tentativa de reduzir os riscos imediatos de agravamento clínico.

\section{Ruídos na comunicação}

entre os acompanhantes e a enfermagem

...se a gente precisar de alguma coisa, ela [acompanhante] vai lá e pede... lógico, todo mundo é ser humano. De vez em quando... sabe que ninguém é perfeito, tem sempre um senão (depoente B).

Neste caso, o senão empregado pelo depoente refere-se à demonstração de descontentamento de alguns membros da equipe ao serem interpelados pelo acompanhante. A reação é diferente quando o próprio paciente solicita a presença, o que sugere a tentativa do isolar e silenciar o acompanhante.

Apesar da reticência do usuário, pode-se perceber a insatisfação com a forma como a equipe reage às solicitações do acompanhante.

É um fato indiscutível que o objetivo comum entre a equipe de enfermagem e o acompanhante a ser almejado é a recuperação do usuário. Porém, observa-se aí a preocupação da instituição equipe de enfermagem em manter-se no controle da internação do usuário, resguardando-se do que possa significar uma intromissão em seu trabalho. Podemos afirmar que neste momento o acompanhante estaria exercendo o papel de instituinte em relação à equipe, no sentido de questionar e provocar a reflexão a respeito de sua participação no atendimento ao enfermo hospitalizado.

O acompanhante, por sua vez, pode sentir-se inseguro quanto aos limites de sua atuação, solicitando a enfermagem repetidamente. Destacase a deficiência na comunicação estabelecida entre as duas partes.

De um modo geral, o acompanhante é leigo em relação à prestação de cuidados em saúde, demandando por parte da equipe uma preparação mínima no que diz respeito às normas de prevenção de infecção cruzada, por exemplo. A função educativa da equipe é primordial, sempre respeitando a dialogicidade na relação e levando em consideração as limitações do outro.

... Só o meu irmão é que uma vez teve um problema com uma enfermeira... mas também ele agiu mal... eu falei pra ele: 'você está errado, não pode reclamar'. Mas ele se alterou sem razão. Ele veio me visitar e trouxe a minha sobrinha, filha dele, que queria ver o tio, fora do horário de visita. Aí a enfermagem barrou eles e ele ficou zangado. A enfermeira também se zangou e não deixou ela entrar. Eu falei pra ele ... eu já não tenho direito a acompanhante porque eu tenho 56 anos. Quem me deu a autorização foi a enfermagem, por causa da necessidade para minha recuperação e você ainda faz isso... Mas no final eles conversaram e então a enfermeira falou: tudo bem, mas ela entra (minha sobrinha) e o Sr. fica aqui fora. Só entra quando ela sair. Depois ficou tudo bem (depoente E).

Os casos de solicitação de acompanhamento que não são previstos em lei, ou seja, de adultos, demanda negociação e sujeição por parte de familiares, que são recebidos com reservas pelo grupo prestador de assistência por ter que dividir o espaço e o tempo hospitalares. No entanto, quando este acompanhamento se coloca no sentido de suprir as necessidades da equipe de enfermagem como, por exemplo, no caso de pacientes desorientados ou com dificuldades em aderir ao tratamento, a receptividade aumenta ou mesmo a presença do acompanhante pode tornar-se uma obrigação para a família.

Como citado anteriormente, a negociação da família para a permissão de acompanhamento em casos não previstos é desgastante. No caso acima, a necessidade de acompanhamento deveu-se a exercícios de fisioterapia respiratória que o usuário necessitava realizar várias vezes ao dia. O acompanhante foi então a solução para o cumprimento do tratamento, que seria comprometido por falta de profissionais de fisioterapia ou de enfermagem disponíveis em tempo integral.

Sendo assim, o usuário submete-se incondicionalmente ao poder da enfermagem sobre o controle de pessoas presentes à unidade, para garantir o seu inquestionável direito à saúde.

Pelo desfecho relatado, ratifica-se a deficiência de diálogo entre as partes, o que só foi possível após enfrentamento desnecessário. É como se equipe e acompanhante estejam vivendo no limite de sua tolerância ao estresse e qualquer discordância no cotidiano seja capaz de desencadear uma explosão.

Observe-se que os segmentos que habitam o hospital vêm se inserindo e disputando espaços ao longo do tempo, o que já lhes garantiu posições de reconhecimento na hierarquia dos estabelecimentos hospitalares. No entanto, o segmento acompanhante, inserido abruptamente por força das orientações da Política Nacional de Humanização $(\mathrm{PNH})^{3}$, permanece ainda à mar- 
gem dos demais atores, sendo necessária a construção coletiva de uma nova racionalidade que o situe nas enfermarias.

...Bom, eles exigiram por que eu tenho idade. Olha, não é bem exigiram, mas eles falaram assim: a pessoa de idade, eu tenho 77, tem que ter um acompanhante. É por isso então... (depoente D).

A partir desse depoimento, apreende-se uma inversão de valores na questão do acompanhamento, ou seja, o que é um direito do usuário é interpretado como dever. Muitas famílias não dispõem de pessoas que possam permanecer no hospital, o que pode ser um grande transtorno. Por vezes são disponibilizados acompanhantes insatisfeitos, que não estão no hospital voluntariamente, pouco contribuindo para o tratamento do usuário.

É importante salientar que a disponibilidade para o acompanhamento transcende a presença física ou a execução de cuidados simplesmente. Devido a isto, muitas vezes é preferível que o usuário permaneça sem a presença de um acompanhante do que em companhia de alguém que não poderia ou desejaria estar ali espontaneamente.

Um agravante para os ruídos na relação entre os acompanhantes e a equipe de enfermagem parece ser a deficiência ou a ausência de clareza na caracterização do que seja um acompanhante. Seria ele um ente físico, apenas com importância presencial no ambiente hospitalar, um indivíduo necessário a minimizar a deficiência de profissionais de enfermagem destinados à vigilância e ao provimento das necessidades de pacientes em condições específicas, um indivíduo a serviço da observação da conduta da equipe de enfermagem a bem da segurança do usuário ou peça importante na engrenagem da internação hospitalar, na recuperação e na reinserção do mesmo?

\section{Enfermagem e condições de conforto para o acompanhante}

A pouca oferta de espaço físico para a acomodação no acompanhante, foi observada durante o trabalho de campo e também identificada nas entrevistas.

... Aqui até que é muito bom. Eu já passei10 dias internado na emergência do [...]. Eu morrendo de dor numa cadeira e ela em pé. Uma coisa horrivel, nem queira saber .... (depoente C).

O fato das unidades cenário deste estudo não apresentarem espaço mínimo para a acomodação de todos os acompanhantes e não haver banheiros destinados exclusivamente aos acompanhantes, não é considerado no depoimento aci- ma pelo usuário. Pelo exposto, a presença de alguém próximo pode ganhar um grau de importância maior que as acomodações oferecidas pelo hospital.

Este núcleo de sentido revelou-se para o usuário como pouco relevante. $\mathrm{Ou}$, pode ser que haja outras questões que atravessam este núcleo localizado na dificuldade de acesso ao serviço de saúde. A problemática de acesso é sempre presente e conseguir uma vaga em um hospital é um direito que tem sido conquistado pela população com muita dificuldade, o que reduz nestes usuários a capacidade de análise sobre a atenção recebida.

Se para a equipe a convivência com acompanhantes pode ser confusa devido à falta de estrutura física da maioria das enfermarias, o acompanhante também pode ressentir-se da falta de conforto, tais como condições inadequadas de repouso, higiene e alimentação, apesar de não declará-lo diretamente. Parece-nos que a figura do acompanhante carece de um perfil que lhe confira identidade, sendo ignoradas as suas necessidades e os seus direitos.

\section{As instituições que atravessam o estudo}

A partir dos núcleos identificados - a presença da enfermagem para o atendimento às solicitações, ruídos na comunicação entre os acompanhantes e a enfermagem e as condições de conforto ao acompanhante - seguiu-se a identificação das principais instituições presentes no contexto analisado. O termo instituição é aqui empregado de acordo com a concepção dos socioanalistas, que afirmam que as instituições seriam normas, transmitidas aos grupos através de regras e regulamentos, podendo ser escritos ou mantidas por hábitos ou comportamentos e que sofrem influência da maneira como os indivíduos concordam em participar destas regras ${ }^{13}$.

Desta forma, foram identificadas como instituições neste estudo o hospital, com suas características peculiares e a equipe de enfermagem.

A mais forte instituição identificada no contexto do processo saúde-doença é o hospital, onde se concentram práticas, políticas, interesses, saberes e instituições menores em seu interior. Ainda hoje o hospital mantém o seu predomínio sobre as ações de saúde, recrutando além da maior quantidade de equipamentos, grande parte do capital destinado a investimentos na área de saúde ${ }^{12}$.

O hospital, neste estudo representado pelo fluxo de relações estabelecidas nas unidades de internação cirúrgicas ou enfermarias, possui um 
conjunto de regras pouco ou nada flexíveis, onde se pode observar, segundo Carapinheiro ${ }^{14}$ :

O impacto da organização sobre os doentes, marcada pelo particular ordenamento dos espaços físicos, pela singular padronização dos tempos cotidianos e pela estrutura de produção de atividades terapêuticas.

O ordenamento do espaço físico aludido pela autora se reflete na assistência ao usuário hospitalizado. Ou seja, a forma compartimentalizada do processo de trabalho baseado no controle do tempo e do movimento pode ser identificada em várias das atividades no hospital. Como o banho no leito, em que se estabelece um período do dia para ser realizado, independente da singularidade do usuário.

A hospitalização constitui-se de uma série de mudanças e interrupções de vida aos usuários que dela necessitam. Os aspectos sociais da hospitalização perpassam pela carência emocional, o isolamento e as dificuldades econômicas quando o sujeito é o responsável pelo sustento de terceiros, o que se torna mais grave em caso de realização de atividades laborais autônomas.

Apesar dos cronogramas pré-estabelecidos, as ações em produção de saúde frequentemente sofrem "distorções" no percurso, capazes de alterar o fluxo da internação de forma incontrolável. Tal fato se deve ao conflito de poderes entre os segmentos prestadores da assistência, visando a manutenção de seus espaços e interesses instituídos ${ }^{15}$.

O usuário, a quem historicamente cabe o papel de paciente, limita-se a acatar e a obedecer às decisões dos profissionais que dele tratam, calando-se. O silêncio, na maioria das vezes, não representa concordância, o que a médio e longo prazo pode atingir um nível de insatisfação não declarada capaz de revelar-se em alterações de quadro clínico ou de comportamento. Estas alterações seriam forças instituintes partindo do usuário, sob as únicas formas possíveis de expressão, muitas vezes interpretadas por profissionais pouco sensíveis como rebeldia injustificada.

Na verdade, as forças instituintes para a Análise Institucional, nada mais seriam do que pressões exercidas pelos grupos ou indivíduos no sentido de questionar, alterar as formas de organização das instituições, sendo por isso as principais responsáveis pelo dinamismo das mesmas.

A segunda instituição identificada no estudo, é representada pelo grupo "equipe de enfermagem”, apresenta-se como uma das responsáveis diretas pela realização da assistência e caracteriza-se por conter profissionais que ditam nor- mas e regulamentos relacionados ao ambiente físico do hospital. Essa instituição traz consigo a imagem positiva da prestação de assistência, mas também o estigma de regras disciplinares do hospital.

Se analisados os antecedentes históricos na composição da dinâmica hospitalar, vemos a perpetuação de regras pesadas, rigorosas, visando manter a ordem vigente e o exercício do poder, anteriormente exercido por cuidadores sem formação técnica, sobre uma clientela desfavorecida e marginalizada ${ }^{16}$. Atualmente, cabe à enfermagem o papel disciplinador e mantenedor da ordem. Entretanto, o trabalho de enfermagem está associado com uma alta demanda assistencial em relação a um número reduzido de profissionais. Um quadro que não favorece o tratamento individualizado do usuário sob seus cuidados.

Algumas características sobre o grupo de enfermagem merecem ser destacadas, como a estrutura interna de organização em classes baseada no nível de formação e o número de profissionais, sendo a maior representatividade da área de saúde.

Emergem do cotidiano dos profissionais de enfermagem agravantes para o prejuízo do relacionamento interpessoal entre si, com o usuário ou com os acompanhantes, tais como as grandes demandas de tarefas administrativas, os procedimentos que envolvem alta tecnologia, a necessidade de agilidade na execução de tarefas -especialmente no cuidar de pacientes críticos ou semicríticos - as jornadas múltiplas de trabalho com prejuízo da qualidade de vida, o subdimensionamento das equipes e o distanciamento emocional inconsciente, que pode ser compreendido como um mecanismo de defesa que facilita o enfrentamento de situações rotineiramente estressantes ${ }^{17}$.

\section{Considerações Finais}

As questões que envolvem o exercício do acompanhamento hospitalar representam um campo fértil para estudos que conduzam à melhoria assistencial, através do aprimoramento do cuidado ao usuário internado, da redução do período de internação e de reinserção do mesmo ao meio social com autonomia.

Detivemo-nos a realizar a análise da situação dos subgrupos a partir do ponto-de-vista do usuário, o que revelou a necessidade de amplas discussões a respeito do papel do acompanhante durante a hospitalização. Tornou-se evidente que 
sua importância, assim como possibilidades de atuação ainda são pouco conhecidas pelos usuários. Os segmentos de acompanhantes e equipe de enfermagem também precisam ser ouvidos e suas percepções analisadas e discutidas detalhadamente.

Posteriores intervenções no coletivo deste hospital poderão surtir efeitos significativos, com benefícios não só para os usuários, mas também para os profissionais e acompanhantes em seu convívio.

Para os estabelecimentos de saúde, o incentivo ao acompanhamento e a implementação da prática de acolhimento a este acompanhante trazem a possibilidade de avançar no objetivo da qualidade em serviço, atendendo não só aos anseios da população a qual prestam a assistência, mas também às orientações preconizadas pelas políticas públicas de saúde e aos organismos de certificação de qualidade.

Em todos os relatos destacados e discutidos, direta ou indiretamente, aparece o número insuficiente de funcionários de enfermagem como causador da demora do atendimento, da "seleção" dos atendimentos por grau de importância, da falta de informações ao acompanhante e da deficiência de diálogo com o acompanhante. Sendo assim, consideramos que o subdimensionamento de pessoal, principalmente de enfermagem, é o analisador que se apresenta para a discussão das questões relativas ao acompanhamento que afligem o usuário.

Tal fato pode encontrar justificativa no número de pacientes designados a cada profissional de enfermagem por plantão, que no hospital em questão extrapola o número recomendado pelo COFEN (Conselho Federal de Enfermagem), o qual estabelece critérios para o dimensionamento do pessoal de enfermagem através da Resolução $293 / 2004^{18}$.

Um estudo de projeção internacional realizado na Pensilvania em 2002 concluiu que para cada usuário adicional por enfermeiro esteve associado $7 \%$ de probabilidade de desfecho fatal nos primeiros 30 dias de internação e $7 \%$ de falha no resgate dos parâmetros fisiológicos buscados com o tratamento. Por outro lado, para o enfermeiro, cada paciente adicional significou aumento em $23 \%$ da probabilidade de desenvolvimento de burnout, doença ocupacional que apresenta sinais e sintomas de exaustão e $15 \%$ de probabilidade de insatisfação com o trabalho ${ }^{19}$. Apesar do estudo não abordar a satisfação do usuário, as consequências do número insuficiente de profissionais de enfermagem nos dão uma projeção dos prejuízos possíveis a esse contingente.

A forma como tem sido conduzida a presença do acompanhante ao usuário hospitalizado de um modo geral e em particular no hospital estudado, nos faz perceber que esta prática ainda não é reconhecida como um direito pelos atores diretamente envolvidos em seu manejo. Ainda se sobrepõe a ideia de que a permanência do acompanhante trata-se de concessão, com vistas a suprir as deficiências estruturais do ambiente hospitalar, sendo ignoradas as necessidades subjetivas dos indivíduos e o valor que o acompanhante pode agregar à recuperação da saúde, da autonomia e à reinserção social do usuário.

Devido ao caráter libertário de ideias e por incentivar a solução de conflitos através do diálogo, defendendo as relações horizontais em ambientes coletivos, a Análise Institucional se mostrou de grande aplicabilidade ao tema estudado. 


\section{Colaboradores}

ICP Sanches e AL Abrahão participaram da concepção, produção da pesquisa e redação do artigo; IRR Couto e M Andrade participaram da coleta, análise de dados e revisão crítica do artigo.

\section{Referências}

1. Brasil. Lei 8080/90 de 19 de setembro de 1990. Dispõe sobre as condições para a promoção, proteção e recuperação da saúde, a organização e o funcionamento dos serviços correspondentes e dá outras providências. Diário Oficial da União 1990; 20 set.

2. Brasil. Ministério da Saúde (MS). HumanizaSUS. Visita aberta e direito ao acompanhante. 2a Edição. Brasília, DF: MS; 2007.

3. Brasil. Ministério da Saúde. Política Nacional de Humanização [online]. [acessado 2010 jul 1]. Disponível em: http://www.saude.gov.br/humanizasus

4. Sanches ICP, Abrahão AL. O acompanhante e os desafios do cuidado hospitalar: acesso ou barreira? Estudo descritivo. Online Braz J Nurs [serial on the internet] 2011 [acessado 2012 nov 4];10(3). Disponível em: http://www.objnursing.uff.br/index.php/ nursing/article/view/3297.

5. Foucault MO. O Nascimento da Clínica. São Paulo: Forense, 2008

6. Baremblitt G. Compêndio de Análise Institucional e outras correntes teoria e prática. Belo Horizonte: Ed. Instituto Felix Guattari; 1992.

7. Minayo MCS. O Desafio do Conhecimento-pesquisa qualitativa em saúde. São Paulo: Hucitec; 2007.

8. Bardin L. Análise de Conteúdo. Lisboa: Edições 70; 2009.

9. Lourau R. A Análise Institucional. Petrópolis: Ed. Vozes; 1975.

10. Brasil. Ministério da Saúde. Conselho Nacional de Saúde. Resolução nº 196 de 10 de outubro de 1996. Diretrizes e Normas Regulamentadoras de Pesquisas Envolvendo Seres Humanos. Diário Oficial da União 1996; out 16.

11. Abrahão AL, Mourão LC, Geisler ARR. O Hospital: um locus de aglutinação profissional. R. Enferm. UERJ 1999; 7(1):68-72.

12. Abrahão AL. O hospital e o Sistema Único de Saúde. A gestão hospitalar na perspectiva da micropolítica. In: Fundação Oswaldo Cruz, Escola Politécnica de Saúde Joaquim Venâncio. Textos de apoio em políticas de saúde. Rio de Janeiro: Fiocruz; 2005. p. 75-98.

13. Lourau R. Analista institucional em tempo integral. São Paulo: Hucitec; 2004.

14. Carapinheiro G. Saberes e Poderes no Hospital. Uma Sociologia os Serviços Hospitalares. Porto: Afrontamento; 1998.

15. Cecílio LCO, Mendes TC. Propstas alternativas de gestão e o protagonismo dos traballhadores: por que as coisas nem sempre acontecem como os dirigentes desejam? Saúde e Sociedade USP 2004; 13(2):33-55.

16. Foucalt MO. Microfísica do Poder. São Paulo: Graal; 2010.

17. Siqueira AB, Filipini R, Posso MBS, Fiorano AMM, Gonçalves AS. Relacionamento enfermeiro, paciente e família: fatores comportamentais associados à qualidade da assistência. ArqMed ABC 2006; 31(2):73-77. 
18. Conselho Federal de Enfermagem. Resolução 293/ 2004 que dispõe sobre o dimensionamento do pessoal de enfermagem para o ambiente hospitalar. [acessado 2012 nov 4]. Disponível em: http:// site.portalcofen.gov.br/node/4329.

19. Aiken L, Clarke S, Sloane DM, Sochalski J, Silber JH. Hospital nurse staffing and patient mortality, nurse burnout and job dissatisfaction. JAMA 2002; 288(16):1987-1993.

Artigo apresentado em 01/03/2012

Aprovado em 27/04/2012

Versão final apresentada em 04/05/2012 